\title{
Correction to: Real-world use of enzalutamide in men with nonmetastatic castration-resistant prostate cancer in Japan
}

\author{
Akira Yokomizo $^{1}$ (1) $\cdot$ Junji Yonese ${ }^{2} \cdot$ Shin Egawa ${ }^{3} \cdot$ Hiroshi Fukuhara $^{4} \cdot$ Hiroji Uemura $^{5} \cdot$ Kazuo Nishimura $^{6}$. \\ Masayoshi Nagata ${ }^{7} \cdot$ Atsushi Saito $^{8} \cdot$ Takumi Lee $^{9} \cdot$ Susumu Yamaguchi $^{8} \cdot$ Norio Nonomura $^{10}$
}

Published online: 1 February 2022

(c) The Author(s) 2022

\section{Correction to: International Journal of Clinical Oncology https://doi.org/10.1007/s10147-021-02070-z}

The article, Real-world use of enzalutamide in men with nonmetastatic castration-resistant prostate cancer in Japan written by Akira Yokomizo, Junji Yonese, Shin Egawa, Hiroshi Fukuhara, Hiroji Uemura, Kazuo Nishimura, Masayoshi Nagata, Atsushi Saito, Takumi Lee, Susumu
Yamaguchi, and Norio Nonomura was originally published Online First without Open Access. With the author(s)' decision to opt for Open Choice the copyright of the article changed on January 31, 2022 to () Author(s) 2021 and the article is forthwith distributed under a Creative Commons Attribution 4.0 International License, which permits use, sharing, adaptation, distribution and reproduction in any
The original article can be found online at https://doi.org/10.1007/ s10147-021-02070-z.

Akira Yokomizo

yokoa@harasanshin.or.jp

Junji Yonese

jyonese@jfcr.or.jp

Shin Egawa

s-egpro@jikei.ac.jp

Hiroshi Fukuhara

hfukuhara-jua@umin.ac.jp

Hiroji Uemura

hu0428@yokohama-cu.ac.jp

Kazuo Nishimura

kazuo.nishimura@oici.jp

Masayoshi Nagata

m-nagata@juntendo.ac.jp

Atsushi Saito

atsushi.saito@astellas.com

Takumi Lee

takumi.ri@astellas.com

Susumu Yamaguchi

susumu.yamaguchi@astellas.com

Norio Nonomura

nono@uro.med.osaka-u.ac.jp
1 Department of Urology, Harasanshin Hospital, 1-8 Taihakumachi, Hakata-ku, Fukuoka 812-0033, Japan

2 Department of Genitourinary Oncology, Cancer Institute Hospital of Japanese Foundation for Cancer Research, 3-8-31 Ariake, Koto-ku, Tokyo 135-8550, Japan

3 Department of Urology, Jikei University School of Medicine, 3-25-8 Nishishimbashi, Minato-ku, Tokyo 105-8461, Japan

4 Department of Urology, Kyorin University School of Medicine, 6-20-2, Mitaka, Tokyo 181-8611, Japan

5 Department of Urology and Renal Transplantation, Yokohama City University Medical Center, 4-57 Urafune-cho, Minami-ku, Yokohama 232-0024, Japan

6 Department of Urology, Osaka International Cancer Institute, 3-1-69 Otemae, Chuo-ku, Osaka 541-8567, Japan

7 Department of Urology, Juntendo University Graduate School of Medicine, 2-1-1 Hongo, Bunkyo-ku, Tokyo 113-8421, Japan

8 Medical Affairs Japan, Astellas Pharma Inc., 2-5-1 Nihonbashi-Honcho, Chuo-ku, Tokyo 103-8411, Japan

9 Development, Astellas Pharma Inc., 2-5-1 Nihonbashi-Honcho, Chuo-ku, Tokyo 103-8411, Japan

10 Department of Urology, Osaka University Graduate School of Medicine, 2-2 Yamadaoka, Suita 565-0871, Japan 
medium or format, as long as you give appropriate credit to the original author(s) and the source, provide a link to the Creative Commons licence, and indicate if changes were made. The images or other third party material in this article are included in the article's Creative Commons licence, unless indicated otherwise in a credit line to the material. If material is not included in the article's Creative Commons licence and your intended use is not permitted by statutory regulation or exceeds the permitted use, you will need to obtain permission directly from the copyright holder. To view a copy of this licence, visit http://creativecommons. org/licenses/by/4.0.

The original article has been corrected.
Open Access This article is licensed under a Creative Commons Attribution 4.0 International License, which permits use, sharing, adaptation, distribution and reproduction in any medium or format, as long as you give appropriate credit to the original author(s) and the source, provide a link to the Creative Commons licence, and indicate if changes were made. The images or other third party material in this article are included in the article's Creative Commons licence, unless indicated otherwise in a credit line to the material. If material is not included in the article's Creative Commons licence and your intended use is not permitted by statutory regulation or exceeds the permitted use, you will need to obtain permission directly from the copyright holder. To view a copy of this licence, visit http://creativecommons.org/licenses/by/4.0/.

Publisher's Note Springer Nature remains neutral with regard to jurisdictional claims in published maps and institutional affiliations. 